\section{The relation between maternal locus of control and coping styles of pediatric leukemia patients during treatment}

\author{
Concetta Polizzi,1,2 Giovanna Perricone,1,2 \\ Valentina Fontana,, 1,2 Paolo D'Angelo, 3 \\ Momcilo Jankovic, ${ }^{2,4}$ Francesca Nichelli, 4 \\ Calogero Taormina, ${ }^{3}$ Sofia Burgio ${ }^{1,2}$ \\ 1Department of Psychology, Educational \\ Science and Human Movement, \\ University of Palermo; ${ }^{2}$ Società Italiana \\ di Psicologia Pediatrica, Palermo; \\ 3Onco-Hematology Unit, A.R.N.A.S. \\ Civico Di Cristina Benfratelli Hospital \\ of Palermo; ${ }^{4}$ Pediatric Hematology Unit, \\ San Gerardo Hospital, Monza, Italy
}

\section{Abstract}

The present study focuses on the relation between coping strategies of children with leukemia during treatment and locus of control of their mothers. In particular, the study aims to determine whether maternal locus of control can influence sick children's coping styles, and if this relation can be used to predict maladjustments. The study analyzed a cohort of 60 pediatric leukemia patients undergoing treatment and a group formed by their mothers. The participants were recruited from two Pediatric OncoHematology Units in Italy. The Child Behavioral Style Scale (CBSS) was used to assess children's coping strategies, whereas the Parental Health Locus of Control Scale (PHLCS) was employed to analyze maternal locus of control. A linear regression model was applied to verify a possible interdependent relationship between children's coping styles and maternal locus of control. The differences in mean CBSS scores were analyzed by K-S test. Multivariate analysis of variance was performed to assess any potential effect of child's gender, hospital context and maternal socio-cultural status on children's coping strategies. Our results show a significant relationship between children's coping strategies and maternal locus of control. In particular, the scales mass media, fate and healthcare professionals display a predictive effect on children's monitoring coping style, given the positive correlation observed $(\mathrm{F}=3.28, \mathrm{P}=0.008)$. In contrast, the same scales negatively correlate with blunting coping style $(\mathrm{F}=3.5, \mathrm{P}=0.005)$. Our results reveal several interesting resources having a profound impact on the psychological functioning of children with leukemia undergoing treatment as well as their mothers. Furthermore, with regard to the central hypothesis of the study, our findings show both positive and negative correlations between specific scales of maternal locus of control and children's coping style, which could be used to predict children at risk of emotional maladjustment.

\section{Introduction}

Parental psychological functioning variables are long-established resources for leukemia pediatric patients undergoing psychosocial adjustment in the course of their illness, especially during the treatment phase. ${ }^{1-9}$ In this regard, numerous studies have shown how the administration of antineoplastic agents can lead to critical developmental impairments due to its adverse effects on healthy cells and tissues. In particular, drug-induced toxicity of the gastrointestinal tract can cause nausea, stomatitis, diarrhea or constipation, whereas hair follicle damage results in alopecia. ${ }^{10,11}$ Other severe side effects induced by the treatment include medullary depression, anemia, hemophilia, often resulting in a general state of immunosuppression, which poses children at high risk of infection. ${ }^{12-14}$

Due to their complex psychophysical state, pediatric leukemia patients in the treatment phase are in dare need of external resources and protective factors that can help them cope with anxiety, fear and depression. ${ }^{15}$ For example, a number of studies have shown how parents' active and adaptive coping strategies make it easier for children to achieve positive coping. ${ }^{16-19}$ That is to say that parental support can aid children in managing critical issues, improving their understanding of critical situations and complying with the instructions of the healthcare team.

Among parental psychological functioning variables relevant to the treatment phase, we focused our attention on maternal locus of control because mothers are typically the main caregivers. More specifically, we referred to the concept of locus of control developed by Rotter, ${ }^{20}$ which defines those factors that are believed to be the causes of positive or negative outcomes of an individual's current state. Rotter's theory is particularly important in light of the distinction it makes between internal and external locus of control: while the former directs a person to look for the cause of what happened "within itself" (e.g., personal variables/characteristics), the latter makes a person believe that what happened
Correspondence: Concetta Polizzi, Department of Psychology, Educational Science and Human Movement, University of Palermo, Viale delle Scienze - Ed. 15, Palermo, 90128, Italy.

Tel. +39.091.23897740 - Fax: +39.091.6513825 E-mail: concetta.polizzi@unipa.it

Key words: leukemia, locus of control, coping children, mothers.

Acknowledgments: The authors are grateful to all children and mothers who participated in the study. They would also like to express their gratitude to all members of the medical and psychological staff involved in the research project.

Contributions: CP, conceptualization, design of the study, data collection and analysis; interpretation of data, writing and reviewing; GP, conceptualization, design of the study, interpretation of data, writing and reviewing; VF, conceptualization, data collection, interpretation of data; PD, MJ, CT, FN, design of the study, data collection; SB, data collection and analysis; all authors have read and approved the final version of this paper.

Conflict of interest: the authors declare no conflict of interests.

Funding: None.

Availability of data and materials: Study database not publicly available. Data available upon reasonable request to the authors.

Ethics approval and consent to participate: The study protocol was approved by the local Ethics Committee.

Informed consent: Informed consent was signed by parents of all patients included in the analysis.

Received for publication: 24 January 2019. Accepted for publication: 9 January 2020.

This work is licensed under a Creative Commons Attribution NonCommercial 4.0 License (CC BY-NC 4.0).

(C) Copyright: the Author(s), 2020

Licensee PAGEPress, Italy

Pediatric Reports 2020; 12:7998

doi:10.4081/pr.2020.7998

is due to external causes (e.g., fate, luck or God).

When applied to health, this theory distinguishes between active individuals, who believe they can implement actions to cope with their illness, and passive individuals, completely unable to adjust to the disease course. Therefore, patients with a prevailing internal locus of control are more likely to attribute their health problems to their own behavior or will. ${ }^{21}$ On the other 
hand, patients with a dominant external locus of control are more likely to attribute the course of events to unpredictable forces, out of their control, such as fate, religion, luck or even healthcare professionals.

Based on Rotter's theory, this study analyses internal and external maternal locus of control, 26 in relation to the mothers' perceived health status of their sick children. ${ }^{27,28}$ This means that some mothers (i.e. active subjects) tend to perceive themselves as being able to deal with the illness and its treatment, whereas others (i.e. passive subjects) feel completely unable to handle the disease and tend to attribute the critical events to external forces such as the aforementioned fate, luck, God or care givers. Furthermore, this study examines children's coping strategies in terms of cognitive, emotional and behavioral styles that can help these young patients manage stressful events during the treatment phase, a very complex contextual and relational situation. According to the Cognitive-Social Health Information Processing (C-SHIP) model developed by Miller,29,30 the coping construct represents a relatively stable characteristic of personality 31 with which to categorize individuals on the basis of their response to stressful events. The different coping styles refer to the need of receiving as much information as possible about the situation to be coped with, or to the need to divert attention from it to keep anxiety and worry in check. In particular, this model defines the construct of coping in terms of the following dichotomic styles: 1) monitoring coping, characterized by attention and sensitiveness to any aspects related to disease; and 2) blunting coping, typified by distraction and cognitive avoidance of distressing aspects. ${ }^{29,30}$ In view of the aforementioned considerations, the present study examines a potential dependent relation between the coping strategies devised by children with leukemia and locus of control of their mothers during the treatment phase, a relation that to our knowledge has never been addressed. Indeed, locus of control has been mainly investigated in other different risk contexts. Our central hypothesis is that maternal locus of control can influence the child's coping style, thereby representing a possible external resource with which to predict positive or negative adjustment to the illness. In this regard, we mainly focus on the treatment phase because of its profound impact on the patient's everyday life. 10,11,22-25 Overall, the goals of the study are the following: 1) to characterize the locus of control configuration of children with leukemia and that of their mothers during the treatment phase; and 2) to determine the presence of a relation between children's coping strategies and specific styles of

\section{Materials and Methods}

\section{Participants}

The study participants were a cohort of 60 children (22 females and 38 males) suffering from acute lymphoblastic leukemia (ALL), acute myeloid leukemia (AML) or lymphoma, with a median age of 10.8 years $(\mathrm{SD}=2.5)$. All patients were examined during the treatment phase at 2 months after diagnosis. The study also involved the children's mothers $(n=60)$, who were all married, with a median age of 41.7 years $(\mathrm{SD}=6.3)$. Regarding their education level, $50 \%$ of them had a high school diploma, whereas $30 \%$ had a secondary school diploma. Only $20 \%$ of mothers had a university degree (Table 1 ).

The recruitment of participants was conducted in two pediatric onco-hematology medical centers of excellence (Palermo and Monza), which have been closely collaborating for many years. Children were selected according to the following inclusion criteria:

- diagnosis of leukemia;

time lapse of about 2 months since diagnosis disclosure;

lack of neurological severe sequelae and genetic syndrome;

age between 8 and 13 years.

Although the number of recruited cases might seem low, these patients amount to almost all the children with leukemia hospitalized in the Palermo and Monza medical centers at the time of the study. Data collection was performed over a 12-month period from 2016 to 2017 .

The research project started after having obtained the approval from the II Ethical Committee of Palermo as well as signed informed consents from both mothers and children. In particular, parents were first asked to give their consent to their children's participation in the study, and then children were asked to sign a specific form, which was read to them by a researcher to explain the meaning of the research, its advantages and the tools that would be administered to them (Table 1).

\section{Tools and procedures}

The tools employed were the following.

1) Child Behavioral Style Scale (CBSS). ${ }^{29,31}$ It was used to investigate the coping styles of children, in terms of monitoring and blunting strategies. Specifically, the monitoring style is typified by the presence of active actions (e.g., asking for information about the disease) and/or adaptive behaviors to face critical and stressful situations, whereas the blunting style is characterized by the presence of distraction strategies and/or cognitive avoidance/negation of the problem.

This tool is a self-report instrument, by way of which children are presented four stress-invoking scenarios referred to typical child's everyday life contexts (e.g., at home, at school, at the pediatrician's office, etc.). Children are requested to choose among 8 suggested possible behaviors per each scenario from a total of 32 by providing a "Yes/No" response.

Based on their answers, we were able to classify children's behaviors in response to stress-invoking situations as related to either monitoring or blunting coping style. For example, in response to the scenario "Your mother has brought you to the physician because you are sick. You are sitting in the waiting room. What would you do?" Children might answer by either adopting a monitoring coping style: "I would tell my mother how sick I'm feeling" or using a blunting one: "I would think of something else to distract me from being sick".

Table 1. Characteristics of the two study groups (children $\mathrm{N}=60$; mothers $\mathrm{N}=60$ ).

\begin{tabular}{lcc} 
Variables & Children Average / SD & Mothers Average / SD \\
Age & $10.8 / 2.7$ & $41.7 / 6.3$ \\
Time lapse since diagnosis, days & $50.8 / 12.4$ & - \\
\hline Presence of other pathologies & $1.9 / 0.37$ & - \\
Gender & & \\
Female \% & 37 & \\
Male \% & 63 & 13 \\
\hline Educational qualification (\%) & & 22 \\
Primary school diploma & & 50 \\
Middle school diploma & & 15 \\
Secondary school diploma & & 100 \\
$\quad$ Post-secondary degree & & \\
Marital status married, \% & &
\end{tabular}


As for psychometric characteristics, the tool has good internal consistency. The dimensions representing blunting behaviors are negatively correlated with those corresponding to monitoring behaviors $(\mathrm{r}=$ $.41, P<.01 ; \mathrm{r}=-.49, P<.01)$. Moreover, the test-retest shows that the test subscales are stable over time $(\mathrm{r}=.72, P<.01 ; \mathrm{r}=.75$, $P<.01)$.

2) Parental Health Locus of Control Scale (PHLCS). 27,28 This tool was used to assess the health status of children. It is a validated and standardized questionnaire for the self-assessment of parental locus of control with regard to children's health status. The tool consists of 28 items subdivided into 6 subscales (i.e. children, parents, healthcare professionals, mass media, fate and God), followed by 6-point Likert scale responses, ranging from $0=I$ totally disagree to $6=I$ totally agree .

As for psychometric characteristics, the tool shows good internal subscale consistency $(\alpha>$.70). In addition, the testretest reliability is appropriate $(r>.80)$.

Before being administered the abovementioned tools, parents were asked to fill in a medical-clinic and social aspect informative form aimed at the collection of parents' and children's medical histories. Parents and children also provided informed consent to their participation in the study and personal data processing.

\section{Data analysis}

For all descriptive, parametrical and non-parametrical statistical analyses, data were codified according to the reference procedures of the tools employed and processed with the Statistical Package for the Social Sciences SPSS (version 20 for Windows). Subsequently, a model of linear regression was applied to verify a possible interdependent relation between children's coping strategies and maternal locus of control. Particularly, the two scales of children's coping (i.e., monitoring and blunting) were treated as dependent variables, whereas the six scales of mothers' locus of control (i.e., children, parents, healthcare professionals, mass media, fate and God) were considered as independent variables.

Statistically significant differences between the two variables monitoring and blunting style of children's coping was assessed by the non-parametric Kolmogorov-Smirnov test for a single sample. A multivariate analysis of variance (MANOVA) was carried out for continuous variables in order to verify the possible effect of children's gender and hospital context (i.e., the hospital where they were being treated) on their most commonly used coping strategies - Scores on the two scales of the CBSS - 2 (gender) x 2 (hospital context). Specifically, the monitoring and blunting scales related to coping were considered as dependent variables, while gender (male/female) and hospital context (i.e., Monza or Palermo) were considered independent variables; the crossed effect of the two independent variables (i.e., gender $\mathrm{x}$ hospital) was also considered. Finally, an additional MANOVA was carried out for continuous variables to verify the possible effect of the social and cultural level of the mothers on locus of control.

\section{Results}

The descriptive analysis of data concerning children's coping strategies by CBSS shows that children were more likely to use monitoring coping than blunting strategies $(\mathrm{M}=17.7, \quad \mathrm{SD}=3.5 ; \mathrm{M}=14.2$, $\mathrm{SD}=3.4$, respectively) (Table 2 ). This means that children reacted to their condition through active coping strategies rather than using avoidance and/or distraction. Fittingly, Kolmogorov-Smirnov test for a sample revealed a statistically significant difference in favor of monitoring coping $(P<.001)$.

The tendency of preferentially using a monitoring style rather than a blunting one while coping characterizes both males (mean monitoring $=18.10, \quad \mathrm{SD}=3.9 ; \quad$ mean blunting $=13.7, \mathrm{SD}=3.8$ ) and females (mean monitoring $=16.95, \quad \mathrm{SD}=2.7$; mean blunting $=15, \mathrm{SD}=2.6$ ), with no statistically significant differences according to gender, as evidenced by the analysis of variance (monitoring: $\mathrm{F}=1.23, \mathrm{P}=.27$; blunting $\mathrm{F}=1.37$ , $P=.24$ ), albeit the descriptive analysis shows a greater tendency to monitoring style for males compared to females.

MANOVA shows that there is no statistically significant difference between the two coping styles used by children as a function of the independent variable hospital context (i.e., Palermo and Monza) (monitoring: $\mathrm{F}=2.25, \quad P=.13$; blunting: $\mathrm{F}=2.20, P=.14)$, although children of the Monza group obtained higher scores on the monitoring scale than those of the Palermo group. This result can be explained by the fact that the two Pediatric Onco-Hematology Units involved in the study, despite having different geographical locations and organizational structures, implement similar procedures for patient management.

The results relative to maternal locus of control obtained by PHLCS are shown in Table 2. By taking into account the different scales of the instrument (i.e., children, parents, healthcare professionals, mass media, fate and God), we observe a double tendency. On the one hand, mothers feel particularly responsible for their children's health (parental scale: $\mathrm{M}=33.9 ; \mathrm{SD}=5.2$ ),

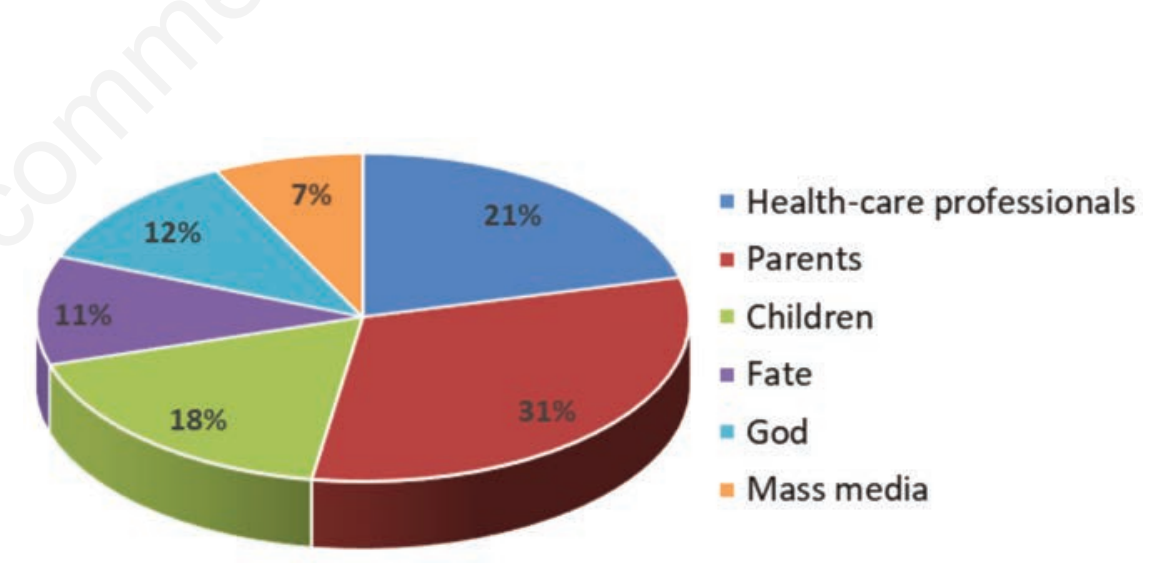

Figure 1. Descriptive statistics: mothers locus of control scales.

Table 2. Descriptive Statistics (children $N=60$; mothers $N=60$ ).

\begin{tabular}{lcc}
\hline Variables & Children Media / SD & Mothers Media / SD \\
Monitoring coping style & $17.7 / 3.5$ & - \\
Blunting coping style & $14.2 / 3.4$ & - \\
\hline Healthcare professionals scale & & $22.8 / 4.3$ \\
$\quad$ Parent scale & $33.9 / 5.2$ \\
Child scale & $19.2 / 5.2$ \\
Fate scale & $11.6 / 7.2$ \\
God scale & $12.5 / 6.1$ \\
Mass media scale & $8.0 / 3.7$ \\
\hline
\end{tabular}


indicating the presence of an internalized locus of control. On the other hand, mothers also believe that their children's health depends very much on the characteristics and behaviors of the medical staff (e.g., adequate communication and technical skills, competence, carefulness, etc.) (healthcare professional scale: $\mathrm{M}=22.8$; $\mathrm{SD}=4.3$ ), attesting the existence of an externalized locus of control. In addition, mothers seem to believe that behavioral and temperamental characteristics play an important role in protecting or not their children's health (children scale: $\mathrm{M}=19.2$; $\mathrm{SD}=5.2$ ). In contrast, the recourse to fate, God and, even less, mass media is less likely to be called into question as a possible source of help (Figure 1).

MANOVA addressing the relationship between the education level of mothers and their locus of control shows statistically significant differences regarding the following scales: 1) healthcare professional scale $(\mathrm{F}=5.6, P=.001)-$ mothers with the lowest educational level obtain the highest average score (Table 3); 2) fate scale $(\mathrm{F}=11.8, P=.001)-$ mothers with a lower level of education have the highest scores (Table 3); God scale (F=2.8; $P=.03)$ mothers with a very low education level (i.e., elementary school diploma) most often resort to the divine to explain what happens to their sick children (Table 3); mass media scale $(\mathrm{F}=6.5, P=.001)$ - mothers with a medium or medium-high education level obtain the highest scores (Table 3 ).

Finally, as for the possible predictive effect of maternal locus of control on children's coping style, which represents the most innovative and interesting hypothesis of the study, data from linear regression analysis show statistically significant relations between the two variables, meaning that the specific variable of psychological functioning of the mothers analyzed in this study (i.e., locus of control style) appears to heavily influence the way children cope with their illness and its treatment. In particular, we found statistically significant relationships only between the PHLOC scales healthcare professional, mass media and fate and the children's coping style. Specifically, each of these maternal locus of control scales correlates positively, in predictive terms, with the monitoring coping style of children $(\mathrm{F}=3.28, P=.008)$, and it clearly correlates negatively with blunting coping style $(\mathrm{F}=3.5, P=.005)$ (Table 4$)$.

\section{Discussion and Conclusions}

The findings presented in this study identify for the first time the existence of specific developmental resources that may help both leukemia pediatric patients undergoing treatment and their mothers adjust to criticalities of patient management, favoring their adaptation process.

A large body of evidence has previously shown how children with leukemia, 31,32 especially those in the treatment phase, tend to adopt a repressive coping style (i.e., avoidance), and therefore have the tendency to inhibit all negative emotions deriving from their critical condition in order to preserve a positive self-image. In addition, according to previous studies, this pediatric population appears unable or unwilling to actively seek information to understand and manage emotional situations. This is in marked contrast with our findings showing that leukemia pediatric patients, despite disease severity and treatment invasiveness, tend to adopt an active and antagonistic behavior rather than an illness-denying one. ${ }^{33}$

Interestingly, on a purely descriptive and qualitative level given the lack of statistical significance, males show a higher level of monitoring coping, which is in line with previous reports. ${ }^{34-37}$ This result can be partly explained by the presence of specific identity development characteristics related to gender. Several studies have in fact highlighted how self-esteem and the concept of self, fundamental processes for identity development, are higher in males than females throughout their life cycle, particularly during childhood and preadolescence. ${ }^{38}$ This is particularly important in light of the fact that the tool used in our study (i.e., CBSS) only measures monitoring coping styles through items that refer above all to cognitive and behavioral activation, thus strictly linked to the use of cognitive strategies and specific resolving behaviors, whereas little attention is paid to emotional coping, which is the main strategy used by females. ${ }^{39}$

The prevalence of a monitoring coping style allows children to develop a positive, hopeful and faithful belief that they will eventually become healthy again, even though at that specific moment of their lives they are experiencing substantial physical and psychological distress caused by the treatment procedures. In addition, children's sensitiveness to the particularity of problems and context, coupled with their need of information, all traits characterizing a monitoring coping style, enable children to look for internal and external resources that can help them cope with their severe condition. Thus, monitoring coping becomes a fundamental internal resource with which to handle the disease as it increases a child's awareness of positive/adverse events related to treatment, thus promoting compliance and positive adaptation. ${ }^{2,40-42}$

In light of the aforementioned, it is likely that an unmanageable appraisal/belief of the disease and its treatment outcome will generate high levels of anxiety and fear in a sick child, which could be nevertheless counteracted by the activation of personal cognitive energies aimed at achieving the best possible adaptation. To gain a better understanding of our findings, we should also consider the data obtained by linear regression relative to the different scales of maternal locus of control and their relationship with children's coping styles. In

Table 3. Descriptive analysis: locus of control scales (mothers $\mathrm{N}=60$ ).

\begin{tabular}{lcccc} 
Locus of control scales & $\begin{array}{c}\text { Primary school } \\
\text { diploma (M;SD) }\end{array}$ & $\begin{array}{c}\text { Secondary school } \\
\text { diploma (M;SD) }\end{array}$ & $\begin{array}{c}\text { High School } \\
\text { diploma (M;SD) }\end{array}$ & $\begin{array}{c}\text { Post-secondary } \\
\text { Degree (M;SD) }\end{array}$ \\
Healthcare professionals & $(28.5 ; 2.07)$ & $(23.2 ; 3.3)$ & $(21.6 ; 4.4)$ & $(21.4 ; 2.9)$ \\
Parents & $(35.1 ; 5.6)$ & $(36.5 ; 3.3)$ & $(32.2 ; 5.8)$ & $(35 ; 2.6)$ \\
\hline Children & $(17.1 ; 1.5)$ & $(19.9 ; 4.2)$ & $(19.4 ; 6.2)$ & $(19.1 ; 5.3)$ \\
Fate & $(22.7 ; 1.03)$ & $(13.9 ; 8.9)$ & $(9.1 ; 5.02)$ & $(6.7 ; 3.03)$ \\
\hline God & $(18 ; 0)$ & $(11.7 ; 7.6)$ & $(10.9 ; 6.2)$ & $(14.4 ; 2.7)$ \\
Mass media & $(3 ; 0)$ & $(8.5 ; 2.1)$ & $(8.7 ; 3.2)$ & $(9.8 ; 4.7)$
\end{tabular}


this regard, while mothers tend to take responsibility for the state of wellbeing/discomfort of their sick children - the parental scale has indeed a higher average score - believing that their own behavior can positively or negatively influence the treatment path, they also tend to hold the child and/or health professionals accountable for what happens (see medium children and healthcare professionals' scales). We are therefore dealing with mothers that probably regard themselves as strong-willed and reassuring, holding themselves responsible for choices and outcomes. On the other hand, these mothers also think that their experiences depend on external factors, out of their control, which makes them believe that health professionals are the sole responsible for treatment outcome.

It should also be noted that quite often this external cause is sought by the child itself, in terms of noncompliant or unresponsive behavior toward the mother's indications. Indeed, the children scale obtained the third highest average score among the locus of control scales, immediately after the parent and the healthcare professional scales.

Overall, our findings support the central hypothesis that some functioning variables of mothers can influence children's coping styles. In particular, linear regression analysis shows that mothers with an external locus of control, who therefore seek external causes (e.g., health professionals, child or fate) to make sense of critical events connected to the condition of their children, are perceived by these latter as fragile and not very capable of taking on responsibility. As a result, these children will be more likely to develop and implement an active coping style characterized by commitment, attention and involvement, actively seeking those resources that adults cannot pursue. Thus, we propose that the presence of an external or internal maternal locus of control determines whether a child will adopt an active $v s$. passive coping style. In the former case, a child would strongly feel the need to act, ask questions, look for information or even reassure its parents (e.g., "I'll make It..." "Don't worry..." "Now I'll be fine...").

In this regard, a potential confounding factor in our study is the fact that the majority of the participants were preadolescents. At this age, children have already acquired a discrete level of selfunderstanding and perspective that enables them to recognize their own resources and understand the difficulties and fragility of their parents. Obviously, this adaptive process would be less likely to occur in younger age children. However, in either case, we believe that the presence of a maternal internalized locus of control, besides promoting an active child's coping style, it would increase the chances that the child would entrust some responsibility to its parent. Overall, our findings indicate that maternal locus of control can be predictive of children's coping strategies, supporting the hypothesis that the parents' beliefs on what affects the course of the disease and treatment can be a helpful external resource for their children's adjustment process. Conversely, given that monitoring coping constitutes a resource for the adjustment of children to their illness course, it is highly likely that a substantial imbalance over time of this process could pose the children at risk of maladjustments.

\section{Clinical implications}

Given the high risk of maladjustment associated with children's monitoring coping style, we strongly recommend that pediatric physicians and psychologists should operate so as to provide sick children with all required resources to gain proper adjustment. This could be achieved, for example, by informing children about their treatment modalities and possible side effects, as previously put forward. ${ }^{45}$ This would also reduce the risk of noncompliance or downright rejection of treatments and prescriptions, as suggested elsewhere. ${ }^{46}$ Indeed, maladjusted children often wish to no longer interact with their attending physicians, ${ }^{47,48}$ and stop being passive and powerless. ${ }^{42}$ In view of the relation between children's coping style and maternal locus of control, healthcare professionals should not just consider the adaptive valence of facing behaviors in children and their mothers but also focus on parental attributions related to the treatment phase. In this regard, convincing a parent that health professionals or fate are not to be considered as the main culprit of its child's poor health could have a positive effect in terms of not only disease management but also positive adaptive behavior of its child. Thus, it is imperative that clinicians and psychologists managing pediatric cancer patients act as an integrated healthcare team at any time of the illness, not just during critical moments (e.g. inefficacy of the treatment or relapse). Indeed, we strongly believe that a truly integrated approach, where communication channels between healthcare professionals are constantly kept open, is the most effective way to provide pediatric patients and their families with the best possible disease management, intercepting all the internal and external resources and promoting change processes. Healthcare professionals should also focus on the coping style of their pediatric cancer patients because this process has an adaptive value, and as such it allows a significant reduction in cortisol levels, often very high due to the numerous stressful events to which the child undergoing treatment is subjected. In the absence of active management of critical events, the child would be left in a prolonged state of stress with high cortisol levels, which would not only risk compromising the responses of the immune system, but it would also interfere with the child's cognitive functioning (e.g., short attention span, memory loss, learning impairment, etc.) and emotional sphere, thereby inducing a depressive state.2,49 It is therefore fundamental that the support for coping should be the primary objective of the integrated work of pediatricians and psychologists. This could be achieved by implementing psychosocial support activities for both children and parents, which would respectively help children develop selfefficacy perception and at the same time provide them with functional security, thus

Table 4. Regression analysis outcomes concerning the effects of maternal locus of control on children's coping styles.

\begin{tabular}{lcccc} 
Predictors & \multicolumn{2}{c}{$\begin{array}{c}\text { Monitoring } \\
\mathrm{R}=.52, \mathrm{R}^{2}=.27, \\
\mathrm{AR}^{2}=.19\end{array}$} & $\mathrm{P}$ & $\begin{array}{c}\text { Blunting } \\
\mathrm{R}=.53, \mathrm{R}^{2}=.28, \\
\mathrm{AR}^{2}=.20\end{array}$ \\
Scales & $\mathrm{B}$ & $\mathrm{P}$ & $\mathrm{P}$ \\
Healthcare professionals & .41 & $.017^{*}$ & -.40 & $.016^{*}$ \\
Parents & -.31 & .10 & .30 & .10 \\
\hline Children & .04 & .85 & -.040 & .85 \\
Fate & .36 & $.010^{*}$ & -.36 & $.009^{*}$ \\
\hline God & .14 & .31 & -.16 & .24 \\
Mass media & .60 & $.004^{*}$ & -.63 & $.002^{*}$ \\
\hline
\end{tabular}

*Statistical significant. 
favoring positive adjustment.

\section{Study limitations}

A limitation of this study is represented by the low sample number, which is however a transversal difficulty in pediatric cancer patient research. Future studies involving other pediatric hemato-oncology excellence centers should warrant the screening of larger populations.

\section{References}

1. Hildenbrand AK, Clawson KJ, Alderfer MA, et al. Coping With Pediatric Leukemia: Strategies Employed by Children and Their Parents to Manage Leukemia-Related Stressors During Treatment. J Pediatr Oncol Nurs 2011;28: 344-54.

2. Miller KS, Vannatta K, Compas BE, et al. The Role of Coping and Temperament in the Adjustment of Children with Leukemia. J Pediatr Psychol 2009;34:1135-43.

3. Klassen AF, Klaassen R, Dix D, et al. Impact of Caring for a Child With Leukemia on Parents' Health-Related Quality of Life. J Clin Oncol 2008:58849 .

4. Norberg AL, Lindblad F, Boman KK. Coping strategies in parents of children with leukemia. Soc Sci Med 2005;60: 965-75.

5. Sawyer M. Childhood leukemia: a 4 year prospective study of the psychological adjustment of children and parents. J Pediat Hematol Onc 2000;22:214-20.

6. Hoekstra-Weebers J, Jaspers J, Kamps $\mathrm{M}$, et al. Risk factor for psychological maladjustment of parents of children with leukemia. J Am Acad Child Psy 1999; 38:1526-35.

7. Grootenhuis MA, Last BF. Adjustment and coping by parents of children with leukemia. A review of the literature. Supp Care Leukemia 1997;3:466-84.

8. Grootenhuis MA, Last BF, De GraafNijkerk JH, et al. Secondary control strategies used by parents of children with leukemia. Psycho-Oncol 1996;5:91-102.

9. Barbarin OA, Hughes D, Chelser MA. Stress, coping and marital functioning among parents of children with leukemia. J Marriage Fam 1985;47:47380 .

10. Zeltzer LK, Blackett-Schlank C. Conquering your child's chronic pain. New York: Harper Collins; 2004.

11. Zeltzer L, Bursch B, Walco G. Pain responsiveness and chronic pain: a psychological perspective. J Dev Behav
Pediatr 1997;18:413-22.

12. Jansen TC, Van Bommel J, Mulder PG, et al. The prognostic value of blood lactate levels relative to that of vital signs in the pre- hospital setting: a pilot study. Crit Care 2008;12:86-107.

13. Tremolada M, Axia G, Bonichini S, et al. Effect of psychological reactions of children affected by LLA cortisone on the sintomathology of parents during reinduction. Haematologica 2007;92:21.

14. Tyc VL, Mulhern RK, Jayawardene D, Fairclough D. Chemotherapy induced nausea and emesis in pediatric leukemia patient: an analysis of coping strategies. J. Pain Symptom Manag 1995;10:33847.

15. Jankovic M, Haupt R, Masera G, et al. La Dichiarazione di Erice. Superare con successo una diagnosi di tumore in età pediatrica. Concetto di guarigione e indicazioni per i controlli a distanza. Eur J Leukemia 2007;43:1778-80.

16. Perricone G, Prista Guerra M, et al. Maternal coping strategies in response to a child's chronic and oncological disease. A cross-cultural study - Italy \& Portugal. Pediatr Rep. 2013;5:43-7.

17. Perricone G, Polizzi C, Morales MR, et al. Percezione del funzionamento familiare e strategie di coping in madri di bambini affetti da neoplasia in fase tratta mentale. Psicologia della Salute. 2013;3:101-13.

18. Polizzi C, Fontana V, Perricone G, et al. Coping strategies and locus of control in childhood leukemia: a multi-centre research. Pediatr Rep 2015;7:22-7.

19. Perricone G, Polizzi C, Morales MR, et al. Functioning of family system in pediatric oncology during treatment phase. Pediatr Hemat Oncol 2012;29: 652-62.

20. Rotter JB. Generalised expectancies for internal versus external control of reinforcement. Psychol Monographs 1966;80:1-28.

21. Donizzetti AR, Petrillo G. Validazione della versione per adulti della Health Locus of Control Scale (HLCS). Psicologia Della Salute. ed. Franco Angeli; 2015.

22. Hamlyn-Wright S, R J. Locus of control fails to mediate between stress and anxiety and depression in parents of children with a developmental disorder. Autism 2007;11:489-501.

23. Allen DG, Weeks KP, Moffitt KR. Turnover Intentions and Voluntary Turnover: The Moderating Roles of SelfMonitoring, Locus of Control, Proactive Personality, and Risk Aversion. J Appl Psychol 2005;90:980-90.

24. Helgeson VS. Moderators of the relation between perceived control and adjustment to chronic illness. J Pers Soc Psychol 1992;63:656-66.

25 . Werner EE. High-risk children in young adulthood: A longitudinal study from birth to 32 years. Am J Orthopsychiat 1989;59:72-81.

26. Tremolada M, Bonichini S, Taverna L, et al. Health Locus of Control in Parents of Children with Leukaemia. Nova Sci Publ 2017.

27. Bonichini S, Axia G, Bornstein, $\mathrm{MH}$. Validation of the parent health locus of control scales in an Italian sample. Ital J Pediatr 2009;35.

28. De Vellis BM, De Vellis RF. Development and validation of the parent health locus of control scale. Health Educ Quart 1993;20:211-25.

29. Miller SM. Monitoring and blunting: Validation of a questionnaire to assess styles of information seeking under threat. J Pers Soc Psychol 1987;52:34553.

30. Miller SM. Monitoring and blunting styles of coping with leukemia influence the information patients want and need about their disease. Leukemia 1995;76: 167-76.

31. Sica C, Magni C, Ghisi M, et al. Coping Orientation to Problems ExperiencedNuova Versione Italiana (COPE-NVI): uno strumento per la misura degli stili di coping. Psicoterapia cognitiva e comportamentale 2008; 14:27.

31. Phipps SD, Mulhern RK. Avoidant Coping in Children with Leukemia. J Pediatr Psychol 1995;20:217-32.

32. Phipps S, Steele RG, Hall K, et al. Repressive adaptation in children with leukemia: a replication and extention. Health Psychol 2001;20:445-51.

33. Scrimin S, Axia V. Processi di adattamento alla malattia tumorale in età pediatrica. In: Axia V. Elementi di psicooncologia pediatrica. Roma: Carocci Faber; 2004.

34. Eschenbeck H, Kohlmann CW, Lohaus A. Gender differences in coping strategies in children and adolescents. J Individ Diff 2007:28:18-26.

35. Lauver DR, Connolly-Nelson K, Vang P. Stressors and coping strategies among female cancer survivors after treatments. Cancer Nurs 2007;30:10111.

36. Matud MP. Gender differences in stress and coping styles. Personal Individ Diff 2004;37:1401-15.

37. Piko B. Gender differences and similarities in adolescents' ways of coping. Psychol Record 2001;51:22335.

38. Santrock JW. Psicologia dello Sviluppo. 
McGraw-Hill; 2008.

39. Tamres LK, Janicki D, Helgeson VS. Sex differences in coping behavior: A meta-analytic review and an examination of relative coping. Personal Soc Psychol Rev 2002;6:2-30.

40. Dowling JS, Hockenberry M, Gregory RL. Sense of humor, childhood leukemiastressors, and outcomes of psychosocial adjustment, immune function and infection. J Pediatr Oncol Nurs 2003;20:271-92.

41. Newby WL, Brown RT, Pawletko TM, et al. Social Skills and Psychological Adjustment of Child and Adolescent Leukemia Survivors. Psycho-Oncol 2000;9:113-26.

42. Wijnberg-Williams BJ, Kamps WA, Klip EC, et al. Psychological adjustment of pediatric leukemia patients revisited: five years later. Psycho-Oncol
2006;15:1-8.

43. Hildenbrand AK, Alderfer MA, Deatrick JA, Marsac ML. A mixed methods assessment of coping with pediatric cancer. J Psychosoc Oncol 2014;32:3758.

44. Kupst MJ, Bingen K. Stress and coping in the pediatric cancer experience. Comprehensive handbook of childhood cancer and sickle cell disease: A biopsychosocial approach. New York, NY: Oxford University Press; 2006. pp 35-52.

45. Nova C, Vegni E, Moja EA. The physician-patient-parent communication: A qualitative perspective on the child's contribution. Patient Educ Couns 2005;58:327-33.

46. Stewart JL, Pyke-Grimm KA, Patterson Kelly K. Parental Treatment Decision Making in Pediatric Oncology. Semin
Oncol Nurs 2005;21:89-97.

47. Spinetta JJ, Masera G, Eden T, et al. Refusal, Non-Compliance, and Abandonment of Treatment in children and adolescents with leukemia. A report of the SIOP Working Committee on Psychosocial issues in Pediatric Oncology. Med Pediatr Oncol 2002;38: 114-17.

48. Spinetta JJ, Jankovic M, Masera G, et al. Optimal Care for the Child With Leukemia: A Summary Statement From the SIOP Working Committee on Psychosocial Issues in Pediatric Oncology. Pediatr Blood Leukemia 2009;52:904-7.

49. Frank NC, Blount RL, Brown RT. Attributions, Coping and, Adjustment in Children with Cancer. J Pediatr Psychol 1997;22:563-76. 